\title{
Long-term Radiological Evidence of Affected and Adjacent Segment Disease after Anterior Cervical Foraminotomy
}

\author{
Yasufumi OHTAKE, ${ }^{1,2}$ Junya HANAKITA, ${ }^{1}$ Toshiyuki TAKAHASHI, ${ }^{1}$ \\ Manabu MinAmI, ${ }^{1}$ Hirohiko NAKAMURA, ${ }^{2}$ and Taigo KAWAOKA ${ }^{1}$ \\ ${ }^{1}$ Spinal Disorders Center, Fujieda Heisei Memorial Hospital, Fujieda, Shizuoka, Japan \\ ${ }^{2}$ Department of Neurosurgery, Spine \& Peripheral Nerve Center, Nakamura Memorial \\ Hospital, Sapporo, Hokkaido, Japan
}

\begin{abstract}
Anterior cervical foraminotomy (ACF) is a surgical procedure for cervical radiculopathy to avoid fusion and adjacent segment disease (ASD), but its long-term outcome has yet to be investigated. It is also unclear whether ACF enables preservation of range of motion (ROM) and decreases ASD compared with anterior cervical discectomy and fusion (ACDF). This study included nine patients who underwent ACF, and 12 who underwent ACDF and with follow-up period of at least 5 years (average follow-up: 8.7 years). Preoperative and postoperative radiological findings were investigated, comparing the changes in ACF versus ACDF. All disc height (DH) levels (C2/3-C7/Th1) were measured preoperatively and postoperatively in all 21 patients to compare with the change due to the natural history. The ACF group experienced significant loss of DH $(0.6 \mathrm{~mm}, 13.5 \%, \mathrm{p}<0.01)$ and $\operatorname{ROM}(\mathrm{p}<0.01)$ at the operated level postoperatively. However, loss of DH was not significantly different from natural changes at unaffected levels, and ROM was maintained. The ACDF group experienced a significant increase in the ROM of the cranial adjacent segment from 6.46 to $7.45 \mathrm{~mm}(\mathrm{p}<0.01)$, and the dislocation in dynamic X-ray was also significantly increased from 1.61 to $2.89 \mathrm{~mm}(\mathrm{p}<0.01)$, indicating radiological ASD. The ACF group had no significant increase in ROM and dislocation. ACF causes significant loss of DH and ROM, but this change is not significantly different compared with natural changes at unaffected levels. Furthermore, ACF causes less ASD than ACDF in the long term.
\end{abstract}

Keywords: anterior cervical foraminotomy, long-term radiological results, adjacent segment disease

\section{Introduction}

There are many procedures used to treat cervical radiculopathy that has not responded to conservative treatment; these options include anterior cervical discectomy and fusion (ACDF), posterior foraminotomy with or without endoscopy, anterior cervical discectomy without fusion, anterior cervical foraminotomy (ACF), and artificial disc replacement. However, it is still unclear which of these procedures is superior. Some surgeons still use posterior foraminotomy for cervical radiculopathy, but the difficulty associated with indirect posterior exposure and the inability

Received April 24, 2020; Accepted June 15, 2020

Copyright@ 2020 by The Japan Neurosurgical Society This work is licensed under a Creative Commons AttributionNonCommercial-NoDerivatives International License. to remove some ventral lesions has led to more frequent use of anterior discectomy procedures. ${ }^{1)}$

ACDF has been widely used, and has become a standard procedure for treating degenerative cervical disease caused by anterior pathologies, but fusion-related problems have also been reported. ${ }^{2-4)}$ ACF aims to achieve direct decompression and to preserve the functional motion of the cervical spine while avoiding fusion-related problems. Some studies have reported excellent results after $\mathrm{ACF},{ }^{5-7)}$ while others have reported that ACF results in reoperation or disc degeneration. ${ }^{8-10)}$ Furthermore, few studies have investigated the long-term results of ACF, and the effect of ACF compared with ACDF on preservation of range of motion (ROM) and adjacent segment disease (ASD) during long-term follow-up. To the best of our knowledge, no previous studies have investigated the longterm radiological incidence of ASD after ACF compared with that after ACDF. The present study evaluated 
the radiological results of ACF for cervical radiculopathy, with a follow-up period of at least 5 years.

\section{Materials and Methods}

From 2004 to 2011, a total of 33 patients with singlelevel degenerative cervical radiculopathy underwent ACF in the Fujieda Heisei Memorial Hospital Spinal Disorders Center. Of these 33 patients, nine patients with at least 5 years of follow-up (mean follow-up period: 8.7 years), affected level was $\mathrm{C} 4 / 5-\mathrm{C} 6 / 7$, and sufficient data were included in the present study as the ACF group. Patients who underwent other procedures during the follow-up period, those lost to follow-up, and those who did not undergo dynamic roentgen stereogrammetric analysis at least 5 years postoperatively were excluded. The ACF group comprised six males and three females, with an average age of 54.5 (range: $32-66$ ) years at the time of surgery. The main pathology was hard disc herniation in two cases, and soft disc herniation in seven. The operated level was $\mathrm{C} 4 / 5$ in one case, C5/6 in three, and C6/7 in five.

The ACDF group comprised 12 patients with singlelevel degenerative cervical myelopathy who underwent ACDF (Cloward's procedure ${ }^{11)}$ ) in Fujieda Heisei Memorial Hospital Spinal Disorders Center during the same period as the ACF group, and were included in the present study as a control group. The ACDF group comprised seven males and six females, with an average age of 49.1 (range: 33-71) years at the time of surgery. The main pathology was hard disc herniation in two cases, and soft disc herniation in 10 . The operated level was C4/5 in two, C5/6 in nine, and C6/7 in one.

\section{Operative indication}

ACF was performed in patients with degenerative single-level unilateral cervical spondylosis or disc herniation with radiculopathy that did not respond to appropriate conservative treatment.

Although there were some reports that patients with cervical myelopathy or spinal tumors, ${ }^{12,13)}$ treated by ACF, we select ACF the case of unilateral radiculopathy. Those with myelopathy or extensive lesions up to the midline who are difficult to achieve sufficient decompression are excluded. Similarly, patients with instability were excluded, and these patients were treated by ACDF.

Radiological confirmation of the underlying pathology by magnetic resonance imaging, myelography, and high-resolution computed tomographic scans after myelography (CTM) was performed in all cases in accordance with the clinical symptoms.

\section{Radiological evaluation}

The following preoperative and postoperative dynamic radiological findings were investigated.
Disc height (DH): The operated segment $\mathrm{DH}$ was measured in the neutral position. DH was measured using the following method. Three parallel lines were drawn: one to the cranial endplate, one to the caudal endplate, and one from the anterior spur to the posterior spur. These lines were used to measure the $\mathrm{DH}$ of the anterior part (A), middle part (B), and posterior part $(\mathrm{C})$ of the disc. Average $\mathrm{DH}$ was defined as $(\mathrm{A})+(\mathrm{B})+(\mathrm{C}) / 3$ (Fig. 1A). In addition, to assess the natural loss of $\mathrm{DH}$ in normal discs, the $\mathrm{DH}$ of all other cervical levels except the operated level (DH all) in all 22 patients was measured in the same way.

Functional segmental height (FSH): In the same way as for the $\mathrm{DH}$ measurements, one parallel line was drawn to the upper endplate of the cranial vertebra, and another was drawn to the lower endplate of the caudal vertebra. The FSH was then measured at the anterior part (A), middle part (B), and posterior part (C) of the segment. FSH was defined as the average of (A), (B), and (C) (Fig. 1B).

The Cobb angle for scoliosis and the focal kyphosis (FK) angle were also measured. ROM and ASD were measured as the changes in focal angle $(\Delta \mathrm{FA})$, and the difference between extension and flexion positions at the operative level ( $\Delta$ Slip), and the difference of spinous process distance ( $\triangle \mathrm{SPD}$ ) (Fig. 1C).

\section{Statistical Analyses}

The data were analyzed via a paired t-test and an independent t-test, and differences were considered statistically significant at $\mathrm{p}<0.05$.

\section{Ethics approval}

The present study was approved by the research ethics committee of Fujieda Heisei Memorial Hospital (permission number: FHR no. 28-3). And the authors obtained written informed consent from patients included in the study at admission.

\section{Surgical procedure}

The patient was placed in the supine position without neck rotation. After confirmation of the affected level, only the longus colli muscle on the symptomatic side was peeled away from the vertebral body. The following surgical procedures were performed using a surgical microscope. The appropriate keyhole position was determined using the findings of CTM coronal sections. This image was used to create a keyhole of about $7 \mathrm{~mm} \times 10 \mathrm{~mm}$, preserving the lateral bone cortex as much as possible, and widely spread in the deep side (Fig. 2). This procedure prevented injury of the vertebral artery. The keyhole made by $3-5 \mathrm{~mm}$ diamond drill was directed toward the root sleeve. The posterior 

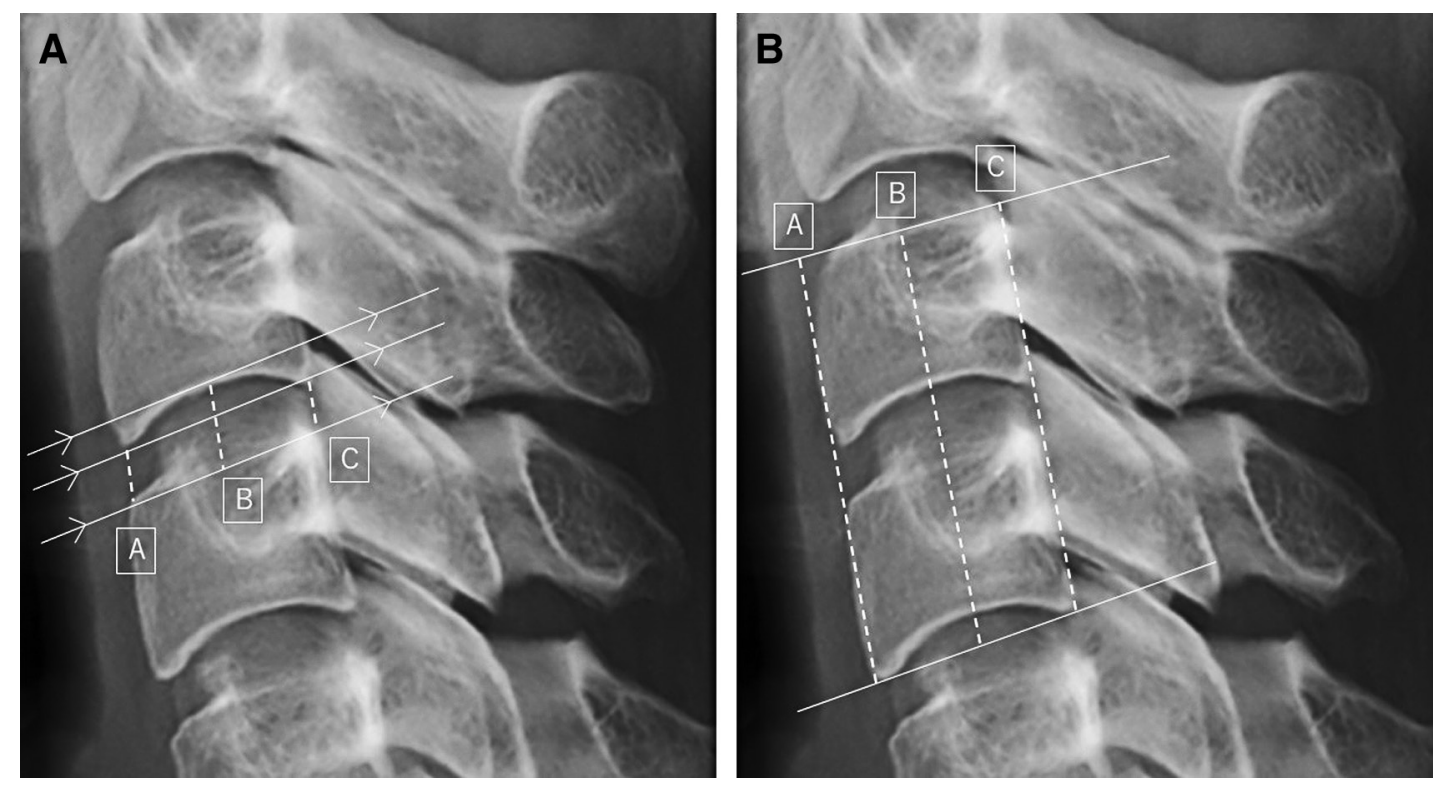

Fig. 1 (A) Measurement methods of DH using plain radiography in neutral lateral position. Three parallel lines are drawn to the cranial end plate, caudal end plate, and anterior to posterior spur and the following are measured: A. ventral end of disc height, B. medial (maximum) disc height, and C. dorsal end of disc height DH was defined as $(\mathrm{A}+\mathrm{B}+\mathrm{C}) / 3$. (B) Measurement methods of FSH using plain radiography in neutral lateral position. We draw two parallel lines to cranial end plate and caudal end plate. A. ventral end of disc FSH, B. medial FSH, and C. dorsal end of FSH. FSH was defined as $(A+B+C) / 3$. DH: disc height, FSH: functional segmental height.

longitudinal ligament and residual cortical bone were removed by micro curette and micro punch. The herniated disc fragment and posterior spur were then gently removed. The residual lateral portion of the pathology was approached from the contralateral side in the last part of operation. A cervical collar was used for 1 week postoperatively.

\section{Results}

\section{Radiographic changes at the affected level}

\section{Disc height}

In the ACF group, the average $\mathrm{DH}$ and the $\mathrm{DH}$ all were significantly decreased after surgery (both $p<0.01$, Table 1). There was no significant difference between the degree of the decrease in $\mathrm{DH}$ and $\mathrm{DH}$ all. Although ACF caused significant loss of DH, this loss was not significantly different from the natural DH loss at other levels (Table 1).

\section{Spinous process distance}

In the ACF group, the average postoperative $\triangle \mathrm{SPD}$ in dynamic X-ray indicated that there was significant loss of ROM at affected level ( $p<0.01$, Table 2); however, a ROM of more than $3 \mathrm{~mm}$ was retained during long-term follow-up. In the ACDF group, the average postoperative $\triangle \mathrm{SPD}$ also indicated that there was significant loss of ROM ( $p<0.01$, Table 2); however, the ROM in all cases was less than $1 \mathrm{~mm}$, indicating that mobility had almost completely disappeared (Table 2).

\section{Functional segmental height}

In the ACDF group, the DH of the operative level could not be assessed postoperatively because of fusion. Thus, we compared the FSH in the ACF group with that in the ACDF group. There was no significant difference between preoperative and postoperative FSH within both the ACF group and the ACDF group (Table 1). Furthermore, the degree of the FSH decrease did not significantly differ between the ACF and the ACDF groups (Table 1).

\section{FK angle}

A postoperative change in FK was seen in both the ACF and ACDF groups, but this change was not significant (Table 1). Furthermore, the degree of the FK change did not significantly differ between the ACF and ACDF groups (Table 1).

\section{Scoliosis}

In the ACF group, there was no significant postoperative change in the scoliosis angle (Table 1). The scoliosis of the operative level could not be assessed postoperatively in the ACDF group because of fusion. 

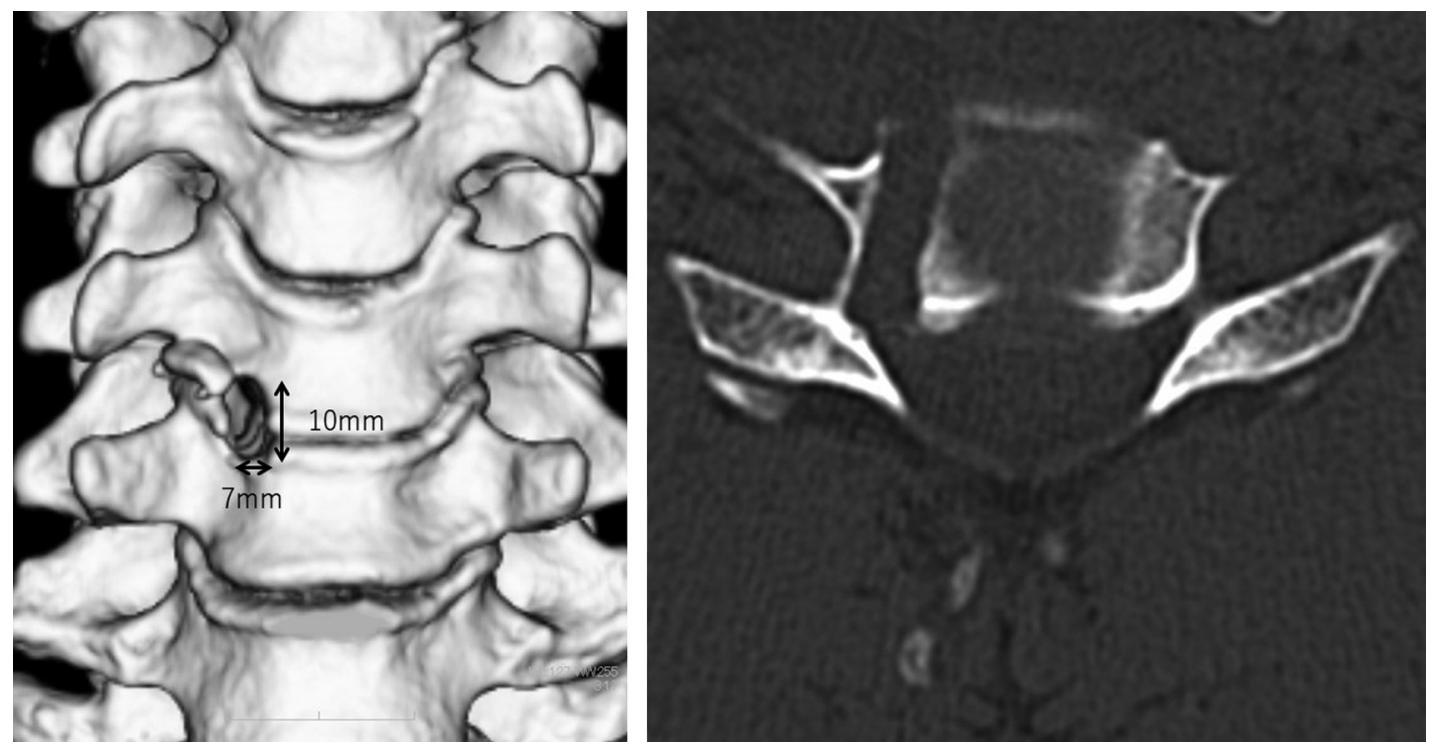

Fig. 2 Key hole in ACF is shown. A $7 \mathrm{~mm} \times 10 \mathrm{~mm}$ keyhole is made in the center of the disc, and with preservation of lateral bone cortex as possible. By this procedure, the injury of VA can be prevented. ACF: anterior cervical foraminotomy, VA: vertebral artery.

Table 1 Radiographical measurements

\begin{tabular}{lccccc}
\hline & Preoperative & Postoperative & $\Delta$ & $\% \Delta$ & $\mathrm{p}$ value \\
\hline DH & $5.36 \mathrm{~mm}$ & $4.77 \mathrm{~mm}$ & $0.58 \mathrm{~mm}$ & $13.5 \%$ Decrease & $<0.01$ \\
DH all & $5.18 \mathrm{~mm}$ & $4.95 \mathrm{~mm}$ & $0.23 \mathrm{~mm}$ & $4.8 \%$ Decrease & $<0.01$ \\
FSH(ACF group) & $37.4 \mathrm{~mm}$ & $34.9 \mathrm{~mm}$ & $1.08 \mathrm{~mm}$ & $3.0 \%$ Decrease & N.S. \\
FSH(ACDF group) & $34.8 \mathrm{~mm}$ & $33.4 \mathrm{~mm}$ & $1.2 \mathrm{~mm}$ & $3.4 \%$ Decrease & N.S. \\
FK(ACF group) & $-0.57^{\circ}$ & $2.01^{\circ}$ & $2.58^{\circ}$ & - & N.S. \\
FK(ACDF group) & $-1.52^{\circ}$ & $0.30^{\circ}$ & $1.82^{\circ}$ & - & N.S. \\
Scoliosis(ACF group) & $0.07^{\circ}$ & $0.86^{\circ}$ & $0.79^{\circ}$ & - & N.S. \\
\hline
\end{tabular}

$\Delta$ : change in, ACF group: patients who underwent anterior cervical foraminotomy ( $\mathrm{n}=9$ ), ACDF group: patients who underwent anterior cervical discectomy and fusion $(\mathrm{n}=12), \mathrm{DH}$ : disc height, DH all: disc height of all other cervical levels except the operated level, FK: focal kyphosis, FSH: functional segmental height, N.S.: not statistically significant.

\section{Focal angle}

There was no significant postoperative change in FA in either the ACF or the ACDF groups (Table 2).

\section{Slip}

In the ACF group, there was no significant postoperative increase in slip at the affected level (Table 2). The slip of the operative level could not be assessed postoperatively in the ACDF group because of fusion.

\section{Radiographic changes at the adjacent levels}

\section{Spinous process distance}

The ACF group showed no significant postoperative changes in SPD at the cranial and caudal levels (Table 2). In the ACDF group, there was a significant postoperative increase in SPD at the cranial and caudal levels ( $p<0.01$, and $\mathrm{p}<0.05$, Table 2), which indicated that ASD had occurred.

\section{Focal angle}

Both the ACF and ACDF groups showed no significant change in FA postoperatively (Table 2). Only the FA at the cranial level in the ACDF group tended to increase postoperatively, possibly to compensate for fusion (ASD).

\section{Slip}

In the ACF group, there was no significant increase in slip at the adjacent levels (Table 2). In contrast, the 
Table 2 Summary of radiographical measurement (ROM)

\begin{tabular}{|c|c|c|c|c|c|c|c|c|c|}
\hline & \multicolumn{5}{|c|}{$\mathrm{ACF}$} & \multicolumn{4}{|c|}{ ACDF } \\
\hline & & Pre Op. & Post Op. & $\Delta$ & $\mathrm{P}$ value & Pre Op. & Post Op. & $\Delta$ & $\mathrm{p}$ value \\
\hline \multirow[t]{3}{*}{$\Delta \mathrm{SPD}$} & Cranial level & $5.75 \mathrm{~mm}$ & $6.29 \mathrm{~mm}$ & $+0.54 \mathrm{~mm}$ & N.S & $6.46 \mathrm{~mm}$ & $7.45 \mathrm{~mm}$ & $+0.99 \mathrm{~mm}$ & $\mathrm{p}<0.01$ \\
\hline & Affected level & $5.89 \mathrm{~mm}$ & $3.79 \mathrm{~mm}$ & $-2.1 \mathrm{~mm}$ & $\mathbf{p}<\mathbf{0 . 0 1}$ & $7.09 \mathrm{~mm}$ & $0.79 \mathrm{~mm}$ & $-6.50 \mathrm{~mm}$ & $\mathrm{p}<0.01$ \\
\hline & Caudal level & $4.14 \mathrm{~mm}$ & $4.47 \mathrm{~mm}$ & $+0.33 \mathrm{~mm}$ & N.S & $6.35 \mathrm{~mm}$ & $5.8 \mathrm{~mm}$ & $0.55 \mathrm{~mm}$ & N.S \\
\hline \multirow[t]{3}{*}{$\Delta \mathrm{FA}$} & Cranial level & $4.9^{\circ}$ & $3.84^{\circ}$ & $-1.5^{\circ}$ & N.S & $5.56^{\circ}$ & $7.17^{\circ}$ & $+1.61^{\circ}$ & N.S \\
\hline & Affected level & $4.89^{\circ}$ & $3.68^{\circ}$ & $-1.21^{\circ}$ & N.S & - & - & - & - \\
\hline & Caudal level & $2.16^{\circ}$ & $0.98^{\circ}$ & $-1.75^{\circ}$ & N.S & $4.82^{\circ}$ & $3.92^{\circ}$ & $-0.9^{\circ}$ & N.S \\
\hline \multirow[t]{3}{*}{$\Delta$ Slip } & Cranial level & $1.89 \mathrm{~mm}$ & $1.84 \mathrm{~mm}$ & $-0.05 \mathrm{~mm}$ & N.S & $1.61 \mathrm{~mm}$ & $2.89 \mathrm{~mm}$ & $+1.28 \mathrm{~mm}$ & $\mathbf{p}<0.01$ \\
\hline & Affected level & $0.91 \mathrm{~mm}$ & $0.8 \mathrm{~mm}$ & $+0.11 \mathrm{~mm}$ & N.S & - & - & - & - \\
\hline & Caudal level & $0.57 \mathrm{~mm}$ & $0.58 \mathrm{~mm}$ & $+0.01 \mathrm{~mm}$ & N.S & $0.86 \mathrm{~mm}$ & $1.8 \mathrm{~mm}$ & $+0.94 \mathrm{~mm}$ & $\mathbf{p}<0.05$ \\
\hline
\end{tabular}

ACF: anterior cervical foraminotomy, ACDF: anterior cervical discectomy and fusion, FA: focal angle, N.S.: not statistically significant, ROM: range of motion, SPD: spinous process distance.

ACDF group showed a significant postoperative increase in slip at the cranial level ( $p<0.01$, Table 2).

\section{Discussion}

\section{Variations of ACF}

Since the technique of ACDF was first introduced, ${ }^{11,14)}$ it has become a standard procedure for treating degenerative cervical disease caused by anterior pathologies. However, fusion-related problems typified by ASD have been reported. Hilibrand et al. ${ }^{4)}$ reported that cervical fusion resulted in symptomatic ASD requiring additional surgery in $2.9 \%$ of patients per year. To avoid this complication of ACDF, the ROM should be preserved as much as possible.

ACF has been developed to preserve the functional motion of the cervical spine while directly removing the underlying pathology; the lateral approach ${ }^{15}$ ) was reported in 1968, and the trans-uncodiscal approach $^{12)}$ was described in 1976. Several kinds of ACF procedures have been advocated, which can be classified into three types. The first type is anterior cervical interspace decompression, which was first reported $^{7)}$ in 1989, and involves an anterior cervical partial discectomy through the disc space; this procedure is most similar to our procedure. The second type is a transuncal approach for anterior microforaminotomy, ${ }^{6)}$ which was first described in 1996, and is performed through the uncinate process to preserve the remaining disc in the intervertebral space directly removing the compressive pathological lesion. Various modifications of the anterior microforaminotomy procedure were later reported, with the upper and lower vertebral bodies more extensively removed. ${ }^{13,16)}$ The third type of ACF is transvertebral ACF, in which a keyhole is created in the vertebral body to enable removal of the underlying pathology. ${ }^{17,18)}$ The common concept of the various types of ACF is to preserve the disc content as much as possible.

\section{Radiological analysis}

Loss of DH after ACF

According to the results of the present study, $\mathrm{DH}$ was significantly decreased postoperatively compared with the preoperative height. As the $\mathrm{DH}$ all was also significantly decreased postoperatively, this loss of DH after ACF may have resulted from the natural changes of the cervical spine; however, it seems to reflect the characteristics of ACF, where the disc space is not filled by any materials, such as iliac bone graft or artificial intravertebral implant. Previous studies have also investigated the outcomes of ACF during long-term follow-up of more than 3 years. Park et al. ${ }^{19)}$ followed up 44 patients for 8.8 years after ACF, and reported a $10 \%$ decrease in DH in $78 \%$ of patients. Kim et al. ${ }^{20)}$ also reported a $1 \mathrm{~mm}$ reduction of $\mathrm{DH}$ in $83.5 \%$ of patients at 6.1 years after ACF. According to these reports and our present results, DH decrease can occur in ACF, but this change is comparable with natural changes in the unaffected spine.

\section{Postoperative change in ROM after ACF}

Although only a few studies have examined the results of long-term follow-up after ACF, there are many short-term follow-up studies. ${ }^{5,6,13,17-19,21-23)}$ These short-term studies report varying results ranging 
from no significant change to significant restrictions in ROM after ACF. This wide variation in reported postoperative ROM may be caused by the lack of a common radiological standard. The ROM of the cervical spine was measured as the C2-7 angle in one study, the FA in another study, and the $\triangle \mathrm{SPD}$ in another study. In the present study, the variables used to assess the ROM were the $\triangle$ SPD and $\triangle F A$. Although the SPD of the operated level significantly decreased after ACF, the ROM was maintained. The FA did not significantly change after ACF. The $\triangle$ SPD was more likely to be significant than the $\Delta \mathrm{FA}$, which was also seen in ASD after ACF and ACDF. This is because the maximum $\Delta \mathrm{FA}$ was $\leq 10^{\circ}$, and these small changes were difficult to distinguish from measurement error.

\section{ASD after ACF}

Many studies have evaluated ASD after ACDF, ${ }^{4,24}$ but there are few reports of radiological ASD after ACF, ${ }^{19,25)}$ Park et al. ${ }^{19)}$ reported that the incidences of radiological ASD after ACF were $6 \%$ and $11 \%$ at the upper and lower segments, respectively. Ahn et al. ${ }^{25}$ also reported that the incidences of radiological degenerative change in the upper segment and the lower segment were both $11 \%$. To the best of our knowledge, no previous study has investigated the radiological incidence of ASD in the long-term period after ACF comparing with ASD in ACDF, as was done in the present study. In our study, ACF resulted in mild increases in SPD, slip, and FA at the adjacent cranial level compared with the respective increases after ACDF. Herkowitz et al. ${ }^{26)}$ evaluated 44 patients with cervical radiculopathy who underwent ACDF or posterior foraminotomy without fusion; $39 \%$ of patients developed radiological ASD after ACDF, while $50 \%$ of patients developed radiological evidence of disc degeneration at the operated and adjacent levels after posterior foraminotomy without fusion. ${ }^{26)}$ Another study evaluating the outcome of cervical arthroplasty reported no significant difference in the ROM of adjacent segments after ACF versus arthroplasty9); however, the follow-up duration was only 1 year. ${ }^{9)}$ It is still unclear which of these procedure is superior in the long term. Further study is needed to investigate the outcome after ACF compared with the other procedures.

\section{Limitations}

This follow-up study includes some limitations, one of which is its small sample size. Because the patients with cervical radiculopathy due to the cervical disc hernia show good postoperative improvement, they do not need to be followed-up for a long time or do not want to consult the clinic postoperatively. So the long follow-up study of the patients with such cervical radiculopathy is difficult to perform.

\section{Conclusion}

ACF causes significant loss of $\mathrm{DH}$ and decrease in $\mathrm{ROM}$ at the operative level during long-term follow-up, but these changes are similar to the natural changes at unaffected levels. Maintaining the motion of the operated segment may impose less stress on the adjacent segments. ASD was mild after ACF compared with ACDF during long-term follow-up. ACF can be an effective surgical procedure for the singlelevel cervical radiculopathy preserving satisfactory postoperative ROM with less adjacent level lesion.

\section{Acknowledgment}

We thank Kelly Zammit, BVSc, from Edanz Group (www.edanzediting.com/ac), for editing a draft of this manuscript.

\section{Conflicts of Interest Disclosure}

The authors declare that there are no conflicts of interest.

\section{References}

1) Henderson CM, Hennessy RG, Shuey HM, Shackelford EG: Posterior-lateral foraminotomy as an exclusive operative technique for cervical radiculopathy: a review of 846 consecutively operated cases. Neurosurgery 13: 504-512, 1983

2) Cho SK, Riew KD: Adjacent segment disease following cervical spine surgery. J Am Acad Orthop Surg 21: 3-11, 2013

3) Gore DR, Sepic SB: Anterior discectomy and fusion for painful cervical disc disease. A report of 50 patients with an average follow-up of 21 years. Spine 23: 2047-2051, 1998

4) Hilibrand AS, Carlson GD, Palumbo MA, Jones PK, Bohlman HH: Radiculopathy and myelopathy at segments adjacent to the site of a previous anterior cervical arthrodesis. J Bone Joint Surg Am 81: 519-528, 1999

5) Choi G, Lee SH, Bhanot A, Chae YS, Jung B, Lee S: Modified transcorporeal anterior cervical microforaminotomy for cervical radiculopathy: a technical note and early results. Eur Spine J 16: 1387-1393, 2007

6) Jho HD: Microsurgical anterior cervical foraminotomy for radiculopathy: a new approach to cervical disc herniation. J Neurosurg 84: 155-160, 1996

7) Snyder GM, Bernhardt M: Anterior cervical fractional interspace decompression for treatment of cervical 
radiculopathy. A review of the first 66 cases. Clin Orthop Relat Res 246: 92-99, 1989

8) Hacker RJ, Miller CG: Failed anterior cervical foraminotomy. J Neurosurg 98: 126-130, 2003

9) Yi S, Lim JH, Choi KS, et al.: Comparison of anterior cervical foraminotomy vs arthroplasty for unilateral cervical radiculopathy. Surg Neurol 71: 677-680, discussion 680, 2009

10) Johnson JP, Filler AG, McBride DQ, Batzdorf U: Anterior cervical foraminotomy for unilateral radicular disease. Spine 25: 905-909, 2000

11) Cloward RB: The anterior approach for removal of ruptured cervical disks. J Neurosurg 15: 602-617, 1958

12) Smith GW, Robinson RA: The treatment of certain cervical-spine disorders by anterior removal of the intervertebral disc and interbody fusion. J Bone Joint Surg Am 40-A: 607-624, 1958

13) Verbiest H: A lateral approach to the cervical spine: technique and indications. J Neurosurg 28: 191-203, 1968

14) Hakuba A: Trans-unco-discal approach. A combined anterior and lateral approach to cervical discs. J Neurosurg 45: 284-291, 1976

15) Jho HD, Kim MH, Kim WK: Anterior cervical microforaminotomy for spondylotic cervical myelopathy: part 2. Neurosurgery 51: 54-59, 2002

16) Jho HD: Failed anterior cervical foraminotomy. J Neurosurg 98: 121-125, 2003

17) Umebayashi D, Hara M, Nakajima Y, Nishimura Y, Wakabayashi T: Transvertebral anterior cervical foraminotomy: midterm outcomes of clinical and radiological assessments including the finite element method. Eur Spine J 22: 2884-2890, 2013

18) Choi G, Arbatti NJ, Modi HN, et al.: Transcorporeal tunnel approach for unilateral cervical radiculopathy: a 2-year follow-up review and results. Minim Invasive Neurosurg 53: 127-131, 2010

19) Park YK, Moon HJ, Kwon TH, Kim JH: Long-term outcomes following anterior foraminotomy for oneor two-level cervical radiculopathy. Eur Spine J 22: 1489-1496, 2013

20) Kim MH: Clinical and radiological long-term outcomes of anterior microforaminotomy for cervical degenerative disease. Spine 38: 1812-1819, 2013

21) Kotil K, Bilge T: Prospective study of anterior cervical microforaminotomy for cervical radiculopathy. J Clin Neurosci 15: 749-756, 2008

22) Sakai T, Katoh KS: Anterior transvertebral herniotomy for cervical disk herniation. J Spinal Disord 22: 408-412, 2009

23) White BD, Buxton N, Fitzgerald JJ: Anterior cervical foramenotomy for cervical radiculopathy. Br J Neurosurg 21: 370-374, 2007

24) Goffin J, Geusens E, Vantomme N, et al.: Long-term follow-up after interbody fusion of the cervical spine. J Spinal Disord Tech 17: 79-85, 2004

25) Ahn JH, Park MS, Kim SM, Chung SY, Lee DS, Park KS: Radiologic changes of operated and adjacent segments after anterior cervical microforaminotomy. Korean J Spine 13: 134-138, 2016

26) Herkowitz HN, Kurz LT, Overholt DP: Surgical management of cervical soft disc herniation. A comparison between the anterior and posterior approach. Spine 15: 1026-1030, 1990

Corresponding author: Yasufumi Ohtake, MD, Department of Neurosurgery, Spine \& Peripheral Nerve Center, Nakamura Memorial Hospital, South-1 West-14 Chuo-ku, Sapporo, Hokkaido 060-8570, Japan. e-mail: yasotk.arcobaleno@gmail.com 